\title{
CHARACTERISTICS OF FINISHED HOLES BY BALLIZING PROCESS
}

\author{
Islam I. Edriys ${ }^{1}$, M. Fattouh ${ }^{2}$ \\ 1 Kaha Company for Chemical Industries, Egypt. \\ 2 Department of Production Engineering and Mechanical Design, Faculty of \\ Engineering, Menofiya University, Shebeen Elkom, Egypt.
}

\begin{abstract}
Ballizing is a method of burnishing an internal diameter by forcing a precision ground steel or a tungsten carbide ball through a slightly undersized pre-machined hole. This plastic deformation process produces a smooth surface with favorable mechanical properties and negative residual stresses. The objective of this investigation is to determine the optimal setting of the ballizing parameters while ballizing 70/30 cu-zn brass alloy. The parameters considered are interference, wall thickness of the hole, number of passes, ball speed and initial surface roughness of the hole, whereas the responses are surface roughness, residual stresses and microhardness variation of the ballized hole. The optimal setting of the parameters is determined through experimental planning, conducted and analyzed using Taguchi method. It is found that the initial surface roughness of the hole exerted the greatest effect on surface roughness of the ballized hole, followed by interference and wall thickness of the hole. The No. of passes and ball speed were found to have only a slight influence on the surface finish. A critical interference $(300 \mu \mathrm{m})$ exists for maximum improvement in roughness. Based on the experimental results, the optimal ballizing for compressive residual stresses were obtained at $4 \mathrm{~mm}$ wall thickness, $400 \mu \mathrm{m}$ interference and $2 \mathrm{~mm} / \mathrm{sec}$ ball speed.The initial surface roughness and No. of passes were found to have no significant effect on the residual stresses. The optimum conditions for surface roughness and residual stresses are different. The microhardness just below the ballized surface was improved up to $65 \%$. The maximum depth of the plastically deformed layer was observed at $300 \mu \mathrm{m}$ below the ballized surface. Generally, it was observed that the maximum value of the strain hardening increases with the increase in both interference and wall thickness. The results of confirmation experiment agree will with the predicted optimal settings.
\end{abstract}

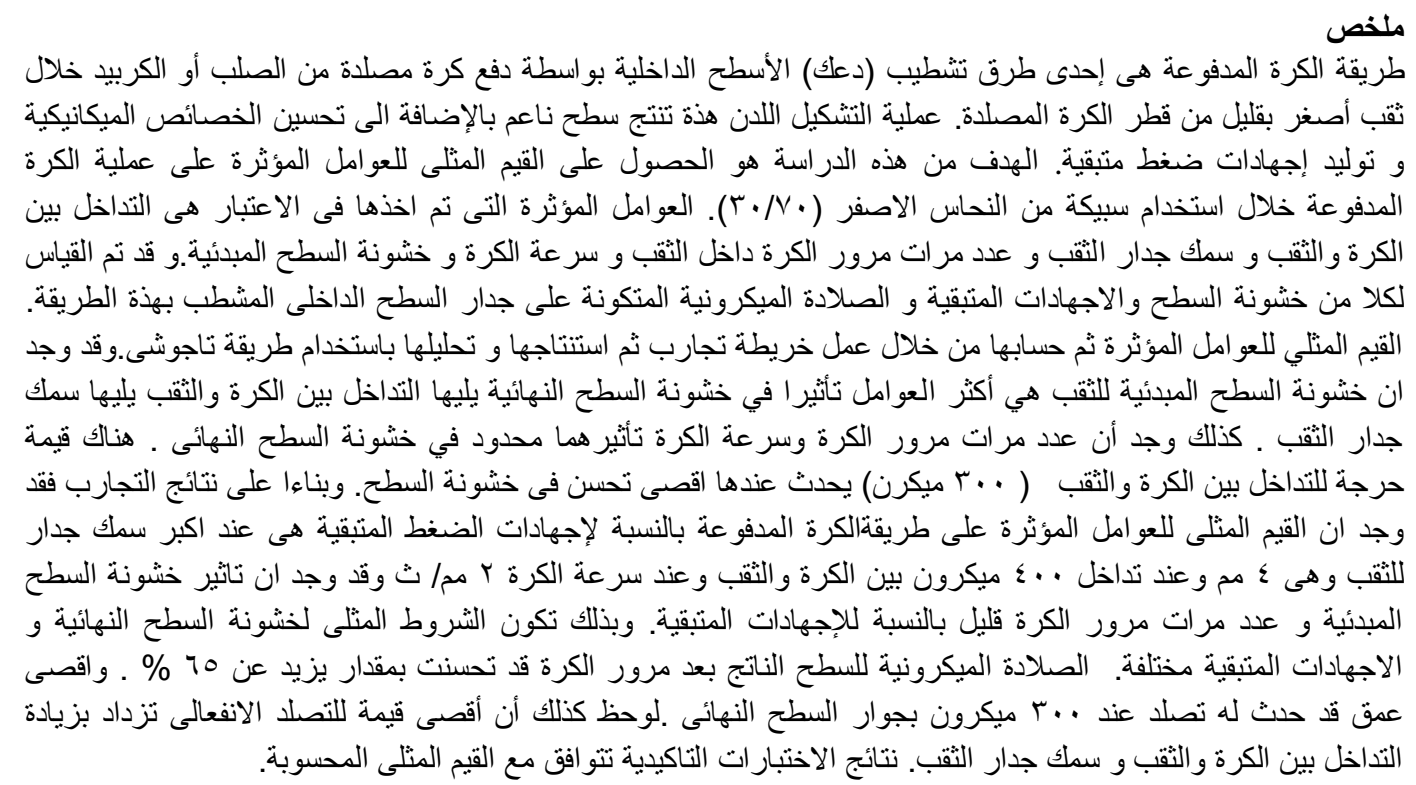

Keyword: Ballizing, Surface roughness, Residual stresses, Microhardness andTaguchi method. 


\section{INTRODUCTION}

Ballizing is a method of burnishing an internal diameter by forcing a ball through a slightly undersized pre-machined hole . As the ball is forced down the hole, material from protrusions is displaced plastically to fill the depressions. The process is also know to induce surface stress which enhances the fatigue life of the component. The cold work imparted during ballizing generates a work-hardened surface which increases wear resistance. The ballizing process requires simple and inexpensive tooling. In addition to hole sizing and surface improvement, ballizing can also be used to swage and flare bush to plate, to press fit two parts together, and to deburr the centre of the hole. The usefulness of the process has prompted several companies to make dedicated versions of ballizing machines . specialist ball suppliers claim to hold a great variety of sizes from $0.5 \mathrm{~mm}$ upwards.

An attempt will be made to review the investigations that have been conducted in the past concerning the effects of some ballizing parameters on surface characteristics of ballized holes.

It is believed that the background for the research undertaken can be developed by focusing attention on this aspect. Gillespie [1] has given a general comparison of three-hole-finishing processes namely: ballizing, lapping with wire, and ball-tipped brushing. Ballizing is a chip less process, and can also be effective for removing loose material at intersecting holes.

Lai and Siew [2] they have presented experimental study to compare three manufacture processes that are able to introduce compressive residual stresses on hole surfaces. The comparison was based on the magnitude of residual stress as well as fatigue life and cyclic tensile loading. The processes investigated are: wet blasting, shot peening and ballizing. With the range of pressure and interference investigated, residual stress measurement revealed that ballizing induced the greatest amount of compressive residual stress. The compressive stress was observed to increase with the interference. The compressive stress decreased and become tensile as the distance from the surface of the hole increased. The residual stresses were evaluated using a fracture mechanics.

Fattouh [3] has carried out an experimental work to investigate the ballizing process. He has developed an experimental relationship to correlate process parameters with the maximum ballizing force. $\mathrm{He}$ reports that the interference value is a critical factor influencing the functional properties of the ballizing surface namely, surface finish, roundness, final diameter, and microhardness.

An important contribution to study the effects of ballizing parameters on the 3-D characterization of the surface topography of the ballizing process was also made by K.H.Wang et al [5]. They have calculated the residual stresses on the circumference of a ballizing ring using the ring cut-off method. They have shown that the wall thickness of the ballizing component and the interference amount are significant causes of roughness and residual stresses. Further more, they found that the speed of the ball (velocity) going through the holes has a little effect on the roughness and residual stress.

El-Abden et al [6] have carried out an experimental work for finishing of non-ferrous holes using a ballheaded tool by holding a tubular specimen on the lathe jaw chuck, rotating it and then pushing an oversized steel ball-shaped tool, clamped to the tool post, into the specimen bore. Rotating speed, feed rate and depth of penetration (Interference) were varied. Variables were optimized with reference to surface quality. They have found that as the interference increased the surface quality improved up to an optimum point after which the surface quality deteriorated.

Nee [7] has constructed a series of nomograms based on modeling equations developed to depict the ballizing process. Such nomograms can be generated easily by inputting the materials properties, interference value, workpiece external to internal diameter ratio etc. In addition, an optimum operating region for achieving maximum improvement in surface finish and roundness is also recommended.

Wang et al [8] have presented an investigation into the mechanism of ballizing process, focusing on the effects of operational parameters on the surface roughness of ballized holes. In this study the two and three-dimensional techniques assessing surface roughness have been applied. The objective was to examine the effect of the initial roughness on the final roughness of ballized surfaces. They have also shown that for manufacturing very fine surface finishes, an initial surface roughness ( $\mathrm{Ra} 1.02 \mu \mathrm{m}$ ) of the workpiece is advised, and applying a large interference $(\mathrm{Ra} 100-160 \mu \mathrm{m})$ would ballized the parts into having a roughness between 0.03 and 0.04 $\mu \mathrm{m}$ in Ra .

Chennakesava et al [9] has given surface roughness and ballizing force as a function of interference. Experiments have been conducted on aluminum and brass specimens using a radial drilling machine. It has been found that spring back varies considerably with different interferences. It was reached to higher the interference larger the spring back, higher the ballizing speed (feed rate) larger spring back.

Nee and.Venkatesh [10-13] have carried out a considerable amount of work concerning with ballizing process. A Study of the ballizing process was made by Nee and Venkatesh [10] , they have used low speed ballizing, tungsten carbide balls of various diameters on brass, aluminum and steel specimens. Surface roughness, roundness and force 
were measured with the large volume of data collected, multiple linear regression techniques were used and empirical relationships were established. Optical and scanning electron microscopy was used for surface integrity studies of surface finish, roundness and forces.

Nee and Venkatesh [11], have used tungsten carbide balls with different lubricants to bring about force reduction. Forces were measured using a strain-gauge dynamometer. Surface deformation was studied by means of scanning electron microscopy. A mathematical model has proposed for the prediction of the final diameters of the ballized hole with experimental observations .

Nee and Venkatesh [12], have also presented a mathematical model based on friction and plasticity theories in the prediction of the final dimensions of a ballized hole. They have found a critical interference, beyond which no further improvement in surface finish was obtainable, can be predicted by the model. This value compares favorably with experimental results.

Nee and Venkatesh [13], have also given a theory proposed for predicting the ballizing load under dry and lubricated conditions. They have been studied the effectiveness of several common lubricants and compared in terms of load reduction and improvement on surface finish.

A number of investigations have been conducted in the past concerning the effects of ballizing parameters on the fatigue life and residual stresses by Lai, Oh and Nee [14-17], The stress analysis of bores that have been cold worked by ballising was studied [14]. The effect of interference on the elastic-plastic zone and the induction of beneficial residual stress were treated theoretically and finally, the effect of ballising on the fatigue life was discussed.

The effect of the residual stress on the fatigue performance of a ballised hole was studied [15]. It has been found that the fatigue performance is dependent upon two factors, namely, the completeness of the ballised hole and the interference between the bore and the ball. The fatigue life was, expectedly, observed to increase with the increase in interference, but when the ballised hole was broken. The fatigue life decreased to below that of an unballised specimen having approximately the same range of surface roughness. Residual stress has been studied using a fracture mechanics approach were conducted to evaluate the residual stress on the ballised hole surface. The result showed that when the hole was complete, compressive residual stress was induced at the hole surface, but when the hole was broken, the compressive stress was redistributed to give tise to a state of tensile stress at the hole surface. This finding was consistent with, and explains, the result of the fatigue tests.
It is considered [16] that residual stresses at the vicinity of a hole evaluated using a fracture mechanics approach, were found to be compressive at the surface and reached maximum tensile stress some $3.5 \mathrm{~mm}$ away from the edge of the hole. By using fatigue test of the ballised and unballised holes showed that the compressive residual stress, together with the improvement in surface roughness of the ballised hole, resulted in a significant increase in the fatigue lives of the ballised holes.

In another study, [17] they have used the theory of plasticity and von Mises yield criterion predicted a resultant compressive stress state surrounding a ballised hole. Experimental investigation with varying interferences into the resultant stress state of a ballised hole in a medium carbon steel concurred with the theoretical predictions.

Lai and He [18] have investigated a detailed stress analysis of a ballized hole. Based on experimental data of ballising, the residual stress field of a ballised hole has been presented and analyzed. It has been found a critical interference value exists between $1.49 \%$ and $1.76 \%$. When the interference exceeded the critical value, reversed yielding occurred at the unloading of the cold working process.

Most of those investigations cited were concerned with the identification of changes in the ballizing process parameters. Also, attempts were made to explain the mechanics of the process. Even in those investigations, where the effects of changes the process parameters have been examined, the approach used has usually be restricted to an examination of the experimental work using one-factor-at-a-time technique. Therefore, detailed descriptions of ballizing process are, in general, lacking. Work conducted to date has not been concerned with attempts to study the ballizing process using design and analysis of experiments (DOE). It is now clear that, when using DOE, the ballizing process is where the need for further fundamental research exists. The general objective of the present investigation is to determine in a comprehensive manner (statistical analysis), the effects of ballizing parameters on the surface integrity during ballizing 70/30 $\mathrm{Cu} / \mathrm{Zn}$ alloy.

This objective will be met through the attainment of the following specific goals, namely;

1- Design the experimental plan using Taguchi method.

2- Measurement of the roughness of the ballized surface.

3- Calculation of the distribution of the residual stresses within the ballized surface region due to sectioning the ring.

4- Measurement of the surface hardness and hardness variation through the ballized surface.

The achieved of the above goals, in conjunction with those obtained from previous work will lead to a better understanding of the performance of the ballizing 
parameters and will aid in the production of surfaces of high integrity.

\section{EXPERIMENTAL INVESTIGATION}

\subsection{Experimental Details}

\subsubsection{Set-up of the Ballizing Process}

A typical set-up of the ballizing process is shown in Fig.(1). A push rod is used to force a ball through the workpiece. The workpiece is not constrained but loosely located in a support. There is no physical connection between the ball and push rod, i.e. the ball remains floating and closely follows the original axis of the workpiece.

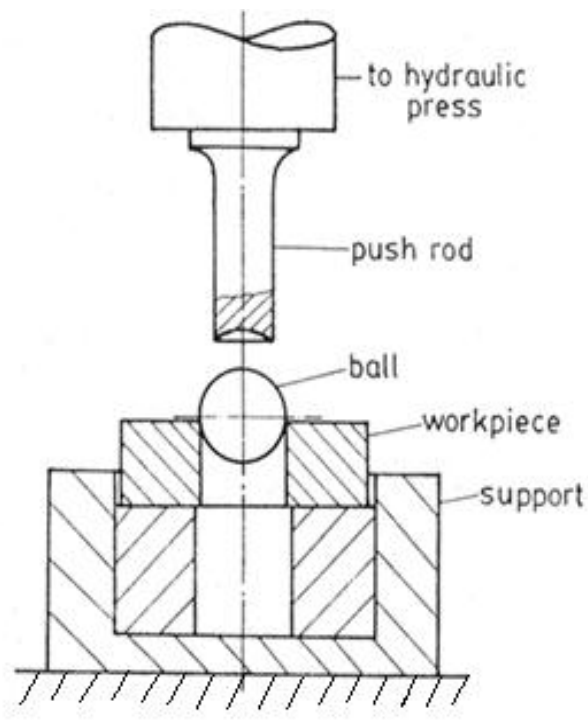

Figure 1. Schematic Arrangement of The Ballizing Process.

\subsubsection{Workpiece Specification}

Workpiece with the following specifications was used: 70/30 cu-zn brass with a tensile yield stress of $284 \mathrm{~N} \mathrm{~mm}^{2}$, Vickers hardness of $(170 \mathrm{hv})$. The material was received in form of tubes, external diameter of $30 \mathrm{~mm}$ and bore of $16 \mathrm{~mm}$. The material was used as -worked. Initial turning conditions were unified for all kind of specimens. Ring-type of workpieces having different wall thickness $(\mathrm{t})$ were used. The height of the workpiece was kept at $10 \mathrm{~mm}$. The initial surface finish ( $\mathrm{Ra}$ ) of the holes before ballizing varied between 1.138 and $3.21 \mu \mathrm{m}$.The holes were turned with interference $(\delta)$ ranging from 0.1 to $0.4 \mu \mathrm{m}$. Four ballizing speeds (V) were applied during this work which were 2,4,6 and 8 $\mathrm{mm} / \mathrm{s}$. This was controlled by adjusting the regulator of a 60 kilo-Newton Press machine. Different ballizing number of passes $(\mathrm{N})$ was used in this investigation. All workpieces were ballized without lubrication. Steel balls, which are usually employed in ball bearing with a diameter of $20.64 \mathrm{~mm}$, were used in this investigation.

\subsection{Experimental Procedure and Measurements 2.2. 1. Surface Roughness}

Surface roughness was measured with the stylus method on a portable surface roughness (Mitotoyo SJ 201) instrument using a meter cut-off length of 0.8 $\mathrm{mm}$. Surface roughness readings were taken at four positions spaced at $90^{\circ}$ intervals around the hole circumference and approximately mid-way down the depth of the ballized hole. In order to correlate the results of the investigation with measurements that might be in a normal production inspection, the arithmetic average surface roughness $\mathrm{Ra}$ was measured.

\subsubsection{Residual Stresses}

In traditional and non- traditional machining operation, a distinctive and rather complex residual stress pattern is imposed on the surface region of the material. Stresses layer may be shallow or deep. There are several ways of determining the residual stress profile introduced by the machining process. The two most common techniques are x-ray diffraction and electrolytic etching deflection .The latter method appears to offer several advantages. For example, it provides an average stress measurement over the entire specimen surface, while the x-ray method can only be used for localized areas. Since it is difficult, if not impossible, to machine specimens that have a uniform stress distribution over the entire surface, a number of areas must be analyzed individually.

In this investigation, the approach to calculate the residual stress is an elasticity solution for a stressed ring. This method was discussed previously and considered that a ring could be analyzed as a curved beam.[19-20]

As the ring is slit, a deflection is induced which is caused by the partial relief of residual stresses in the ballized ring will deflect the ring after cutting. Figure (2) shows the ballized ring and a typical segment of the ring as a free body in equilibrium. The deflection $(\delta)$ has three component, those due to bending $(\mathrm{M})$, axial load, (P) and transverse shear (V). (F) is an imaginary horizontal force in the direction of deflection.

The measured deflection can be used to calculate the relative distribution of the residual stress by using eqn. (1) and variation the value of $r$ between $r=r 1$ to $\mathrm{r}=\mathrm{r} 2$ ( $\mathrm{r}=\mathrm{r} 1$ at ballizing surface , $\mathrm{r}=\mathrm{r} 2$ at outside diameter of the ring).

$$
\sigma_{\theta}=\frac{\delta E}{4 \pi_{0}\left(r_{2}^{2}-r_{1}^{2}\right)}\left(\frac{-r_{1}^{2} r_{2}^{2}}{r^{2}} \ln \frac{r_{2}}{r_{1}}+r_{2}^{2} \ln \frac{r}{r_{2}}+r_{1}^{2} \ln \frac{r_{1}}{r}+r_{2}^{2}-r_{1}^{2}\right)
$$

$\sigma_{\theta}=$ circumferential stress due to sectioning the 
ring

$$
\begin{aligned}
& r_{0}=\text { mean radius }\left(\boldsymbol{r}_{1}+r_{2}\right) / 2(\mathrm{~mm}) \\
& r_{1}=\text { inside radius of the ring }(\mathrm{mm}) \\
& \boldsymbol{r}_{2}=\text { outside radius of the ring }(\mathrm{mm}) \\
& \delta=\text { deflection }(\mathrm{b}-\mathrm{a})(\mathrm{mm})
\end{aligned}
$$

Due to the fact that the deflection reflects only the partial relief of residual stresses in the workpiece this equation cannot be used to obtain the absolute value of residual stress of the ballizing surfaces but through this approach it can obtain the relative value of the residual stresses and find the comparative trends which are reflected by the different operational parameters. For each individual tests the following procedure was used to calculate the deflection $(\delta)$ :

1. Two lines, about $10 \mathrm{~mm}$ apart, were drawn across the surface of the ring with a sharp marker. The distance between these two lines (a) was accurately measured on the Vickers metallogragh.

2. A small section, about $3 \mathrm{~mm}$ in length, was cut from the ring, between the two lines drawn in step 1 above. This slit caused a partial relief of the residual stress that, in turn, produce deflection of the free ends of the ring.

3. The change in the distance between the two lines, due to sectioning the ring (b), was measured on an optical microscope.
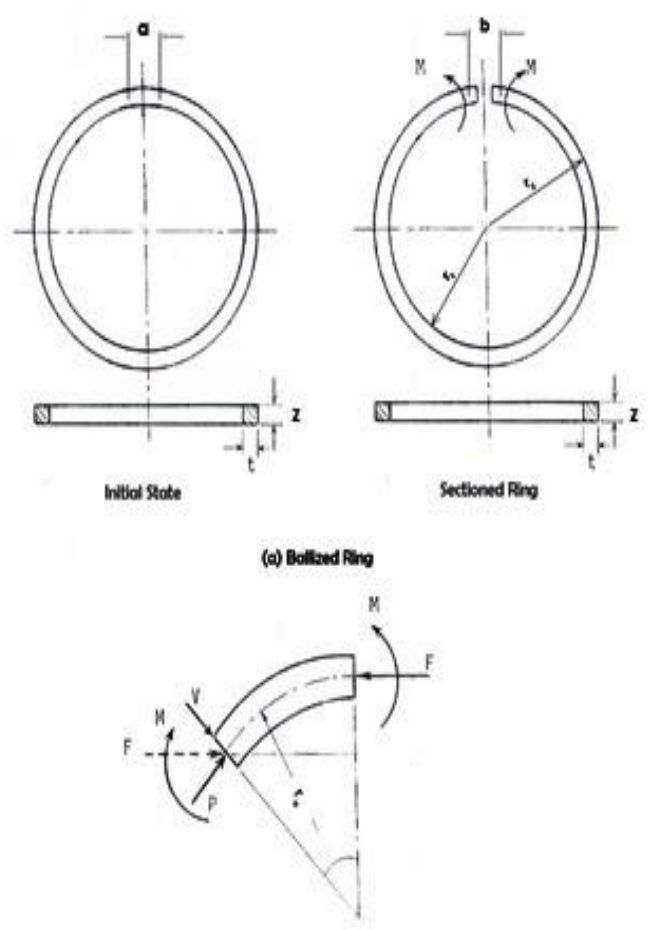

(b) Free Body Diagram

Figure 2. Ballized Ring Piece and a Segment Free Body Diagram

\subsubsection{Microhardness Variation}

Microhardness profiles across the surface region were made for some ballizng conditions used in this investigation. Sections approximately $5 \mathrm{~mm}$ in length were cold mounted such that a plain section perpendicular to the ballized surface and parallel to the direction of ball motion was exposed. The specimen was mechanically polished. On each specimen, a microhardness survey was made from the ballized surface to a depth of approximately 600 $\mu \mathrm{m}$ beneath the surface using a Vickers Diamond Pyramid microhardness tester attached to the Vickers mettalogragh. A load of 25 grams and holding time 10 seconds were used. In addition the bulck hardness of each specimen was also measured.

\subsection{Experimental Plan Based on Taguchi Method}

In order to investigate the effect of various process parameters on the performance of process and then to suggest the optimal process settings, statistically designed experiments are used in this work. The Taguchi method is devised for process optimization and identification of optimal combinations of factors for given responses [21-22]. In this study, five ballizing parameters, were selected as control factors. These factors were chosen based on review of literature, experience, and some preliminary investigations. Each factor was designed to have four levels, denoted 1,2,3,4. The code and levels of control factors are shown in Table 1. A standard Taguchi experimental plan (orthogonal array) with notation L16 (4) was chosen. Table 2 shows the experiments involved in the orthogonal array and the accompanying level assignments for each experiment. The first column was assigned to the interference $(\delta)$ and the second column to the wall thickness of the hole (t) and the third column to the number of passes through the hole $(\mathrm{N})$ and the fourth column to the ball speed (V) and the fifth column to the initial surface roughness (SRi).

Table1. Control Factors (Ballizing Parameters) and Their Levels:

\begin{tabular}{|l|l|r|r|r|r|}
\hline \multirow{2}{*}{ Factor } & \multirow{2}{*}{ Parameter } & \multicolumn{4}{|c|}{ Level } \\
\cline { 3 - 6 } & & 1 & 2 & 3 & 4 \\
\hline$\delta$ & Interference $(\mathrm{mm})$ & 0.1 & 0.2 & 0.3 & 0.4 \\
\hline $\mathrm{t}$ & Wall thickness $(\mathrm{mm})$ & 1 & 2 & 3 & 4 \\
\hline $\mathrm{N}$ & No. of passes & 1 & 2 & 3 & 4 \\
\hline $\mathrm{V}$ & Ball speed $(\mathrm{mm} / \mathrm{s})$ & 2 & 4 & 6 & 8 \\
\hline $\mathrm{SFi}$ & Initial surface finish $(\mu \mathrm{m})$ & 3.21 & 1.138 & & \\
\hline
\end{tabular}


Table 2. Orthogonal Array of L16 (4):

\begin{tabular}{|c|c|c|c|c|c|c|c|c|c|c|}
\hline \multirow{3}{*}{$\begin{array}{l}\text { EXP. } \\
\text { No }\end{array}$} & \multicolumn{10}{|c|}{ Level of Control Factors } \\
\hline & \multicolumn{2}{|l|}{$\delta$} & \multicolumn{2}{|l|}{$\mathrm{t}$} & \multicolumn{2}{|l|}{$\mathrm{N}$} & \multicolumn{2}{|l|}{ V } & \multicolumn{2}{|c|}{ SFi } \\
\hline & Cod. & Act. & Cod. & Act. & Cod. & Act. & Cod. & Act. & Cod. & Act. \\
\hline 1 & 1 & 0.1 & 1 & 1 & 1 & 1 & 1 & 2 & 1 & 3.21 \\
\hline 2 & 1 & 0.1 & 2 & 2 & 2 & 2 & 2 & 4 & 1 & 3.21 \\
\hline 3 & 1 & 0.1 & 3 & 3 & 3 & 3 & 3 & 6 & 2 & 1.138 \\
\hline 4 & 1 & 0.1 & 4 & 4 & 4 & 4 & 4 & 8 & 2 & 1.138 \\
\hline 5 & 2 & 0.2 & 1 & 1 & 2 & 2 & 1 & 2 & 2 & 1.138 \\
\hline 6 & 2 & 0.2 & 2 & 2 & 1 & 1 & 2 & 4 & 2 & 1.138 \\
\hline 7 & 2 & 0.2 & 3 & 3 & 4 & 4 & 4 & 8 & 1 & 3.21 \\
\hline 8 & 2 & 0.2 & 4 & 4 & 3 & 3 & 3 & 6 & 1 & 3.21 \\
\hline 9 & 3 & 0.3 & 1 & 1 & 3 & 3 & 4 & 8 & 1 & 3.21 \\
\hline 10 & 3 & 0.3 & 2 & 2 & 4 & 4 & 3 & 6 & 1 & 3.21 \\
\hline 11 & 3 & 0.3 & 3 & 3 & 1 & 1 & 2 & 4 & 2 & 1.138 \\
\hline 12 & 3 & 0.3 & 4 & 4 & 2 & 2 & 1 & 2 & 2 & 1.138 \\
\hline 13 & 4 & 0.4 & 1 & 1 & 4 & 4 & 2 & 4 & 2 & 1.138 \\
\hline 14 & 4 & 0.4 & 2 & 2 & 3 & 3 & 1 & 2 & 2 & 1.138 \\
\hline 1) & 4 & 0.4 & 3 & 3 & 2 & 2 & 4 & 8 & 1 & 3.21 \\
\hline 16 & 4 & 0.4 & 4 & 4 & 1 & 1 & 3 & 6 & 1 & 3.21 \\
\hline
\end{tabular}

\section{RESULTS AND DISCUSSION}

A series of ballizing tests was conducted to assess the influences of ballizing parameters on the surface characteristic. For the elaboration of experiments plan the method of Taguchi for four factors at four levels and one factor at two levels was used. The measured values and the corresponding $(S / N)$ ratios for experimental trails are shown in Table (3). The $(S / N)$ ratio for each experiment was calculated by applying Eqn. (2).

$$
\begin{array}{r}
\eta_{i, j} \\
-10 \log \left(\mathrm{L}_{\mathrm{i} . \mathrm{j}}\right)
\end{array}
$$

Where $L \mathrm{i}, \mathrm{j}$ is the loss function. In the case of the lower-the-better L i,j can be expressed as [21-22]

$$
L_{i, j}=\frac{1}{n} \sum_{i=1}^{n} y_{i, j, k}^{2}
$$

and $\boldsymbol{Y}_{\boldsymbol{i}, \boldsymbol{j}, \boldsymbol{k}}$ is the experimental value of the $i_{t h}$ performance characteristic in the $\boldsymbol{j}_{\boldsymbol{t} \boldsymbol{h}}$ experiment at the $\boldsymbol{k}_{\boldsymbol{t} \boldsymbol{h}}$ test. The loss function of the higher-the-better can be expressed as [21-22].

\begin{tabular}{|c|c|c|c|c|}
\hline EXPNo. & S.R, $\mathrm{Ra}(\mu \mathrm{m})$ & S.R $(\mathrm{S} / \mathrm{N})$ & R.S (MPa) & R.S (S/N) \\
\hline 1 & 2.63 & -8.39 & 25.10 & 27.99 \\
\hline 2 & 2.06 & -6.27 & 31.76 & 30.03 \\
\hline 3 & 0.64 & 3.87 & 50.30 & 34.03 \\
\hline 4 & 0.57 & 4.88 & 63.20 & 36.01 \\
\hline 5 & 0.87 & 1.20 & 35.54 & 31.01 \\
\hline 6 & 0.84 & 1.51 & 38.99 & 31.81 \\
\hline 7 & 1.85 & -5.34 & 101.76 & 40.15 \\
\hline 8 & 1.80 & -5.10 & 65.00 & 36.25 \\
\hline 9 & 1.26 & -2.00 & 72.50 & 37.20 \\
\hline 10 & 1.09 & -0.74 & 130.23 & 42.29 \\
\hline 11 & 0.35 & 9.11 & 158.71 & 44.01 \\
\hline 12 & 0.28 & 11.05 & 258.24 & 48.24 \\
\hline 13 & 0.54 & 5.35 & 74.51 & 37.44 \\
\hline 14 & 0.44 & 7.13 & 118.42 & 41.46 \\
\hline 15 & 1.07 & -0.58 & 240.20 & 47.61 \\
\hline 16 & 0.82 & 1.72 & 215.80 & 46.68 \\
\hline
\end{tabular}

$$
L_{i j}=\frac{1}{n} \sum_{i=1}^{n} \frac{1}{y_{i, j, k}^{2}}
$$

Table 3. Results of Experimental Plan: (Ra)

- SR: Surface roughness after ballizing ,

- R.S: Surface Residual stresses, (MPa)

The objective of using the $(S / N)$ ratios as a performance measurement is to develop products and process insensitive to noise factor. The noise is usually due to the un-controllable factors, which exist in the environment often cannot be eliminated, and which cause variation in the output. Noise factors are difficult, impossible, or expensive to control

\subsection{Effect of Ballizing Parameters on Surface Roughness}

After completing the experiments, the next step in the data analysis is to determine the near optimum level of each control factor and its percentage contribution, and provides a better feel for the relative effect of the different factors on experimental response. The analysis was using the popular software specifically used for design of experiment applications known as Minitab 16. The analysis is done by averaging the raw and/or $(S / N)$ data at each level of each factor 
and plotting the values in graphical form. The main effects of raw data and those of the $(S / N)$ response table for surface roughness are shown in Fig.(3), and Table (4).Regardless of category of the quality characteristic, a grater $(S / N)$ ratio corresponds to a better performance. The level of a factor with the heights $(S / N)$ ratio is the near optimum level .

Table 4. Response Table for $(\mathrm{S} / \mathrm{N})$ ratio of Surface Roughness:

\begin{tabular}{|c|c|c|c|c|c|}
\hline Level & $\delta$ & $\mathrm{t}$ & $\mathrm{N}$ & $\mathrm{V}$ & $\mathrm{SFi}$ \\
\hline 1 & -1.479 & -0.961 & 0.989 & 1.11 & -3.34 \\
\hline 2 & -1.931 & 0,404 & $1.35^{*}$ & 0.772 & $5.517^{*}$ \\
\hline 3 & $4.354^{*}$ & 1.766 & 0.973 & $1.515^{*}$ & \\
\hline 4 & 3.404 & $3.139^{*}$ & 1.035 & 0.95 & \\
\hline Delta & 6.286 & 4.100 & 0.376 & 0.743 & 8.860 \\
\hline Rank & 2 & 3 & 5 & 4 & 1 \\
\hline Contribution & $30.86 \%$ & $20.15 \%$ & $1.81 \%$ & $3.63 \%$ & $43.53 \%$ \\
\hline
\end{tabular}

- * denote the best level (near optimum)

- Delta $=(S / N) \max -(S / N) \min$,

- Contribution $=\left(\right.$ Delta $/ \sum$ Delta $) \%$

- Over all mean $(S / N)$ ratio $=1.0872 \mathrm{~dB}$

It is clear from Table (4) that the parameter values at levels $\delta 3, \mathrm{t} 4, \mathrm{~N} 2, \mathrm{~V} 3$, and Rai2 are best choice in terms of surface finish. Therefore, the near optimal parameter combination level is interference at level $300 \mu \mathrm{m}$, wall thickness at level $4 \mathrm{~mm}$, number of passes at level 2 ,ball speed at level $6 \mathrm{~mm} / \mathrm{s}$, and initial surface finish at level $1.138 \mu \mathrm{m}$. Since this combination of factor levels was not listed in the OA, a confirmation experiment must be performed. The effect of each control factor is computed from the value of delta, based on which Table (4) shows that factor (SRi) initial surface roughness has the largest delta and thus has the most significant influence (Rank 1) on the surface roughness. From the analysis of Table (4) it was observed that the percentage contribution of the control factors in the decreasing order is (1) SFi $(43.53 \%)$, (2) $\delta(30.86 \%)$,(3) t $(20.15 \%)$, (4) V (3.63\%) and (5) N (1.81\%). The comparatively small magnitude of this residue contribution indicates that the surface roughness is mainly dominated by the three control factors, i.e., the initial surface finish, the interference, and wall thickness in order of decreasing contribution. The level average response from the raw data helps in analyzing the trend of performance characteristic with respect to the variation of the factor under study. The relative slope of the linear graphs indicates significance of the parameters. Here, the slope of the graph, showing the influence of initial surface roughness on surface finish, is more compared to other graphs. Hence the initial surface roughness is the most significant parameter, followed by interference and wall thickness. The overall mean of the main effects is $1.06 \mu \mathrm{m}$.

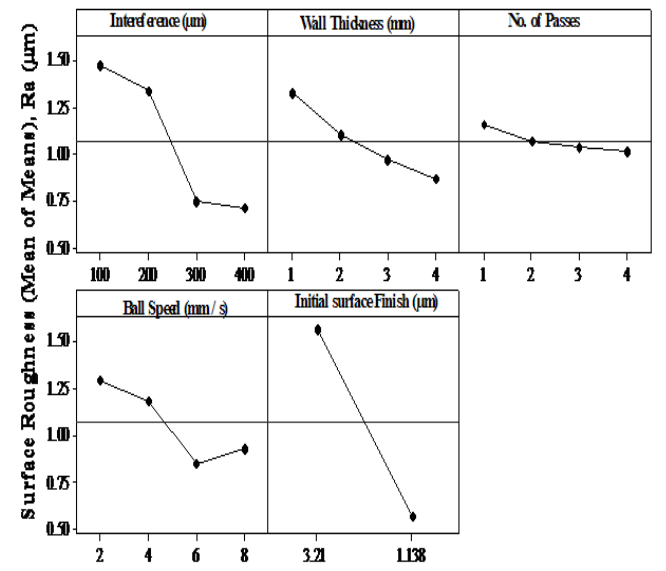

Figure 3. Effect of Control Factors on Surface Roughness. ( Main Effect Plot )

The effect of interference and initial surface roughness on the surface roughness of ballized holes is shown in Fig.(4). It can be seen that for a given interference a decrease in initial surface roughness improves the final surface roughness of the ballized ring. It can also be seen that the surface roughness decrease with an increase in interference to a minimum at $300 \mu \mathrm{m}$. with a further increase in interference, the surface roughness increases slightly.

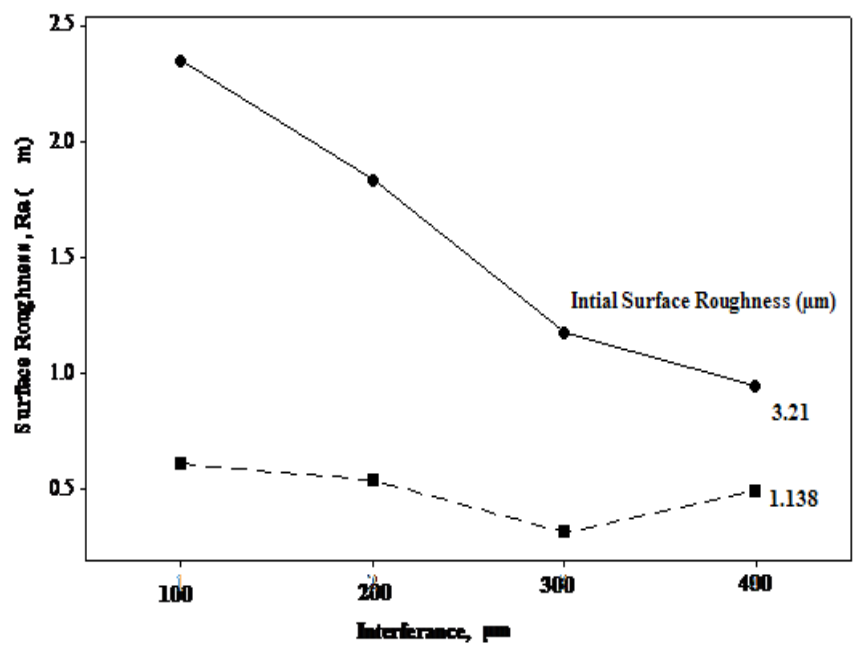

Figure 4: Effect of Interference and Initial Surface Roughness on Final Surface Roughness. 
The relationship between the wall thickness and surface roughness for two different initial surface roughness is shown in Fig.(5). It can be seen that by increasing the wall thickness, the surface roughness decrease as continuously. it can be seen from Fig.(4) and Fig.(5) that for manufacturing fine surface finishes, a fine initial surface finish of the workpiece is advised.

These figures show a general reduction tendency in roughness. The surface finish reduces with a reduction in wall thickness at constant initial surface roughness. This case expresses the effect of wall elasticity on the development of ballized surface roughness. The thicker the wall thickness, the less the wall elasticity and more the surface finish improvement.

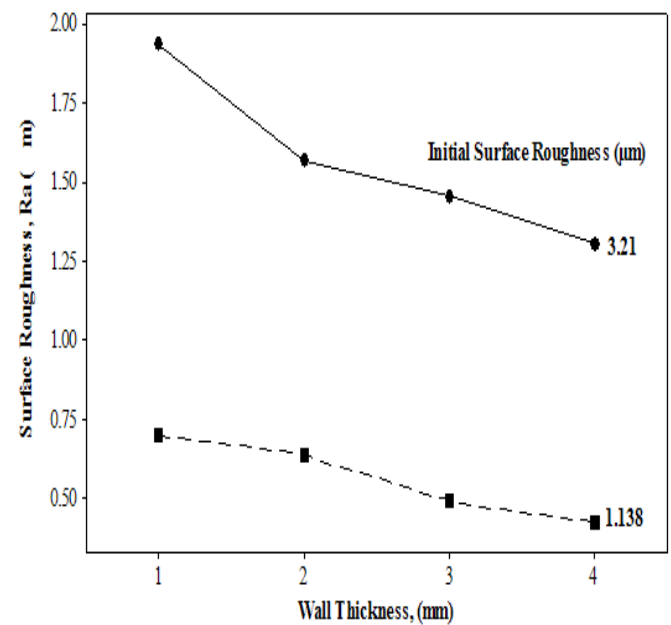

Figure 5: Effect of Wall Thickness and Initial Surface Roughness on Final Surface Roughness.

The interference required to cause complete plastic deformation of the ring depends on both material properties and the wall thickness. When the wall thickness is small, a small interference is sufficient to complete plastic deformation as material can expand. readily outwards. The experimental results indicate that no significant improvement in surface finish can be achieved when interference exceed that which is required to cause complete plastic deformation of the ring, any excessive interference would only mean high ballizing force and possible damage of ring material. A normal probability plot of the surface roughness is shown in Fig. (6). Since the data point lie approximately along the straight line, we do not suspect any severe non normality in the data. There are no indications of severe outliers. Because the data points roughly follow the straight line, and all points fall within the confidence bands, so the residual are normal. It can be concluding that the data are forming a normally distributed.

These results are qualitative agreement with the experimentally measured surface roughness, that have been presented by [3,5 and 7$]$.

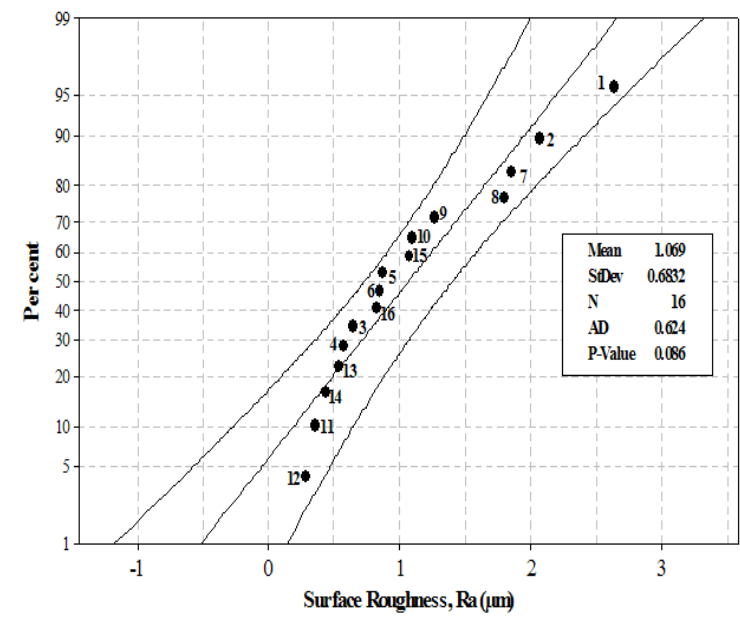

Figure 6. Normal Probability Plot of Surface Roughness.

\subsection{Effect of Ballizing Parameters on}

Residual Stress Distribution

The graphical representation of the effect of ballizing control factors on surface residual stress is shown in Fig.(7). The $(S / N)$ ratio response table is shown in Table (5). It is evident from Table (5) and Fig.(7) that factors $\delta, \mathrm{t}$ and $\mathrm{V}$ can be treated as significant factors where as factor $\mathrm{N}$ and Rai are less significant factors. Analysis of the results leads to conclusion that factors at level $\delta 4, \mathrm{t} 4$ and $\mathrm{V} 1$ can be set for obtaining the maximum compressive residual stress at the ballized surface.

Table 5. Response Table for $\mathrm{S} / \mathrm{N}$ Ratio of Residual Stress

\begin{tabular}{|c|c|c|c|c|c|}
\hline Level & \multicolumn{1}{|c|}{$\boldsymbol{\delta}$} & $\mathrm{t}$ & $\mathrm{N}$ & $\mathrm{V}$ & $\mathrm{SF}$ \\
\hline 1 & 32.02 & 33.41 & 37.63 & $39.46^{*}$ & $38.53^{*}$ \\
\hline 2 & 34.81 & 36.40 & $39.29^{*}$ & 36.94 & 38.01 \\
\hline 3 & 42.94 & 41.45 & 37.24 & 38.51 & \\
\hline 4 & $43.30^{*}$ & $41.80^{*}$ & 38.98 & 38.16 & \\
\hline Delta & 11.28 & 8.38 & 1.98 & 2.53 & 0.52 \\
\hline Rank & 1 & 2 & 4 & 3 & 5 \\
\hline Contribution & $45.68 \%$ & $33.94 \%$ & $8.02 \%$ & $10.25 \%$ & $2.10^{\%}$ \\
\hline
\end{tabular}


"

- $\quad$ * denote the best level (near optimum) level

- Delta $=(S / N) \max -(S / N) \min$,

- $\quad$ Contribution $=\left(\right.$ Delta $/ \sum$ Delta $) \%$

- $\quad$ Over all mean for $(S / N)$ ratio $=38.26$ $\mathrm{dB}$

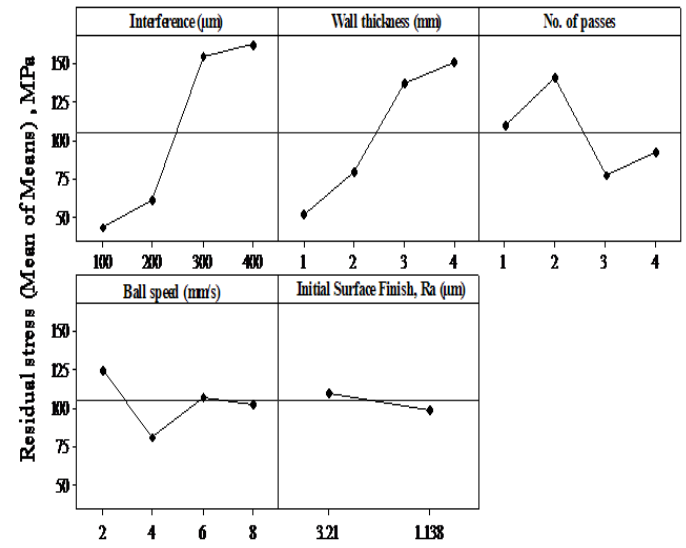

Figure 7. Effect of Control Factors on Residual Stresses. ( Main Effect Plot)

The variation of the residual stress at ballized surface (maximum compressive stress) with interference, for different wall thickness, is shown in Fig. (8). For workpieces having wall thickness $2 \mathrm{~mm}$ and $4 \mathrm{~mm}$, it can be seen that surface residual stress (maximum compressive stress) increases with an increase in interference.

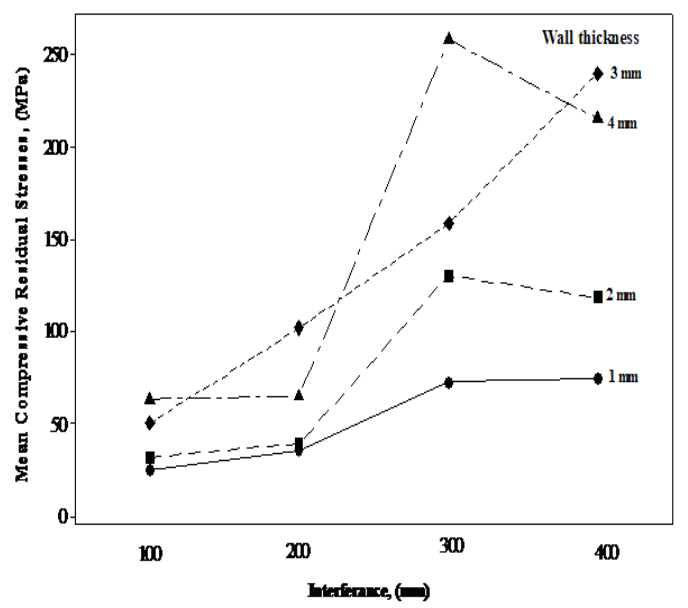

Figure 8. Effect of Interference and Wall Thickness on Residual Stresses (due to sectioning the ballized ring)
Figure (8) shows the trend for $1 \mathrm{~mm}$ and $3 \mathrm{~mm}$ wall thickness workpieces. The trend illustrates the bigger the interference amount, the higher the surface residual stress induces obviously this phenomena illustrates the effect of the wall thickness elasticity. The $4 \mathrm{~mm}$ wall thickness specimens have no wall elasticity and in the case of $1 \mathrm{~mm}$ thickness, considerable wall elasticity is evident which induces spring back after ballizing and releases a large part of the residual stress.

A normal probability plot of the compressive residual stress is shown in Fig. (9). since the data point lie approximately along the straight line, it is not suspect any severe non normality in the data. There are no indications of severe outliers. Since, the data points roughly follow the straight line, and all points fall within the confidence bands, so the compressive residual stress are normal. It can be conclude that the data are a normally distributed.

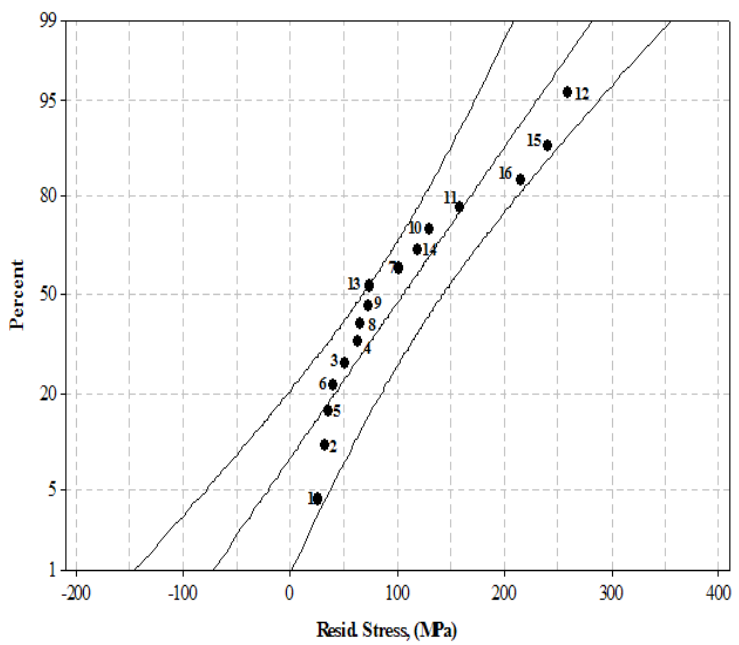

Figure 9. Probability Plot of Compressive Residual Stress.

The present work involves an investigation of residual stress distribution in the surface region of ballized workpieces under different ballizing conditions. However, because of the similarity of the general trend of the results for each ballizing condition used, the detail results for some ballizing conditions are presented in Fig.(10) and Fig.(11) . Equation (1) was used to calculate the residual stress distribution due to sectioning the ballized ring. Figure (10) shows the residual stress distribution in the surface region at constant wall thickness with different interference . It can be seen that the residual stress at the ballized surface is maximum (compressive) and decreases very rapidly to minimum value (negligible) at the mean radius of the ring. The (tensile) residual stress then starts and increases gradually with a further increase in the wall thickness tending to become maximum at out side diameter of the ring. However, at a constant wall thickness the residual stress are much lower when 
"

using interference of $200 \mu \mathrm{m}$ than when using interference of $400 \mu \mathrm{m}$.

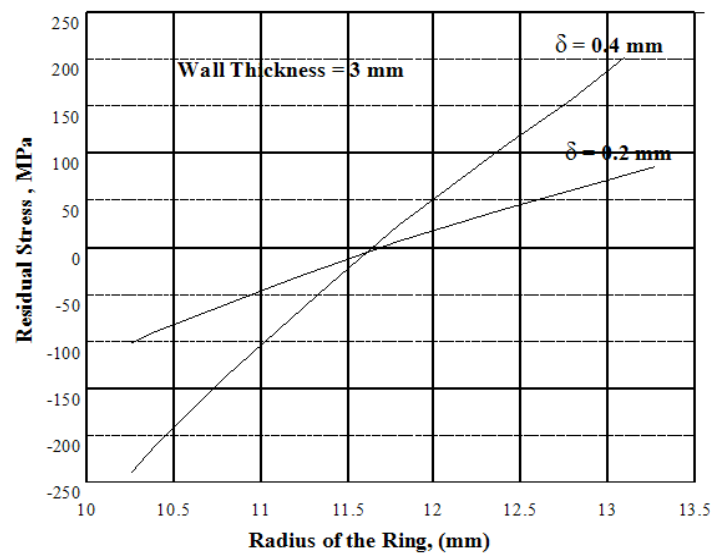

Figure 10. Effect of Interference at Constant Wall Thickness on Residual Stress Distribution.

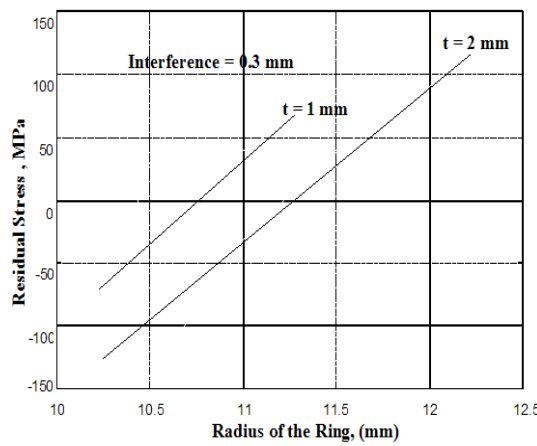

Fig

ure 11. Effect of Wall Thickness at Constant Interference on Residual Stress Distribution.

Figure (11) shows the residual stress distribution at a constant interference and different wall thickness. It can be seen that the residual stress behave in similar manner to those found in Fig. (10). However, at a constant interference the residual stress are much higher when using thicker workpieces. The maximum residual stress for all ballizing conditions used considerably lower than the ultimate and yield strength of the material. It can be seen from Fig.(10) and Fig.(11) that the ballized surface residual stress are, in general, high. It is believed that this is attributed to the plastic deformations that are quite large at the ballized surface and decrease with an increase in depth beneath the ballized surface. Residual stresses at vicinity of the hole were found to be compressive at the surface and reached maximum tensile stress at the outside diameter of the ring. This result is qualitative agreement with those evaluated using a fracture mechanics approach [16].

\subsection{Effect of Ballizing Parameters on Micro Hardness Variation}

It was found when ballizing under different ballizing conditions, that a very thin disturbed or plastically deformed surface region was produced. Microhardness variation within the surface region was made for some ballizing conditions. Figure (12) shows the microhardness distribution through the surface region of three ballized specimens.

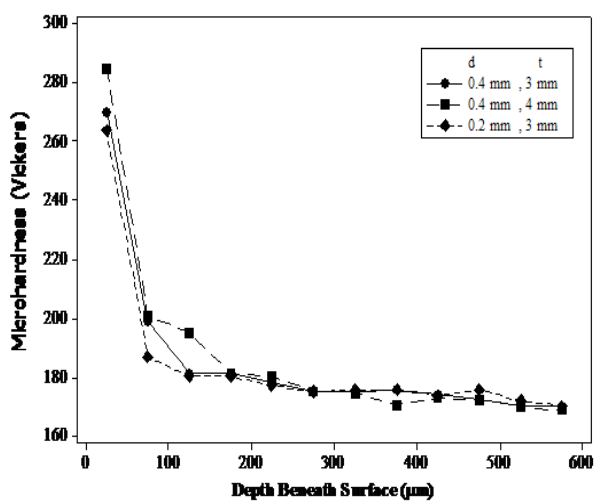

Figure 12. Microhardness Distribution Through Surface Region.

It can be seen for all cases, that the microhardness just below the ballized surface is high. It decreases with an increase in the depth beneath the ballized surface eventually reaching the bulck hardness of the work material .

The strain hardening index (SHI) is defined as: local hardness/hardness of bulck material. The SHI represents the degree of strain hardening and eliminates the effects of the variations of the original hardness of the material and variation in the preparation of the specimens.

The material is hardened if $\mathrm{SHI}>1$, is softened if $\mathrm{SHI}<1$, is not changed if $\mathrm{SHI}=1$. Therefore the depth of the plastically deformed layer can be detected by locating the depth where $\mathrm{SHI}=1$. Figure (13) shows the strain hardening variation with the depth beneath the ballized surface for two specimens having the same wall thickness but ballized at different interference. It can be seen that the strain hardening indexes close to ballized surface are larger than unity and decrease continuously with increasing depth beneath the surface until the bulck hardness is attained (SHI =1). Figure (14) shows the strain hardening variation for two specimens having different wall thickness and ballized at the same interference. Generally, it can be seen that the maximum value of the strain hardening increases with an increase in both interference and wall thickness. Plastic deformations are quite large at the ballized surface. Thus, it would be expected that the 
strain hardening will be maximum at the surface .It's value then decreased very rapidly to a minimum at depths in the range of $250 \mu \mathrm{m}$ below the ballized surface (the depth of the plastically deformed layer) and tending to become constant. It can also be seen from these figures that the hardness variation follows a similar trend for all cases.

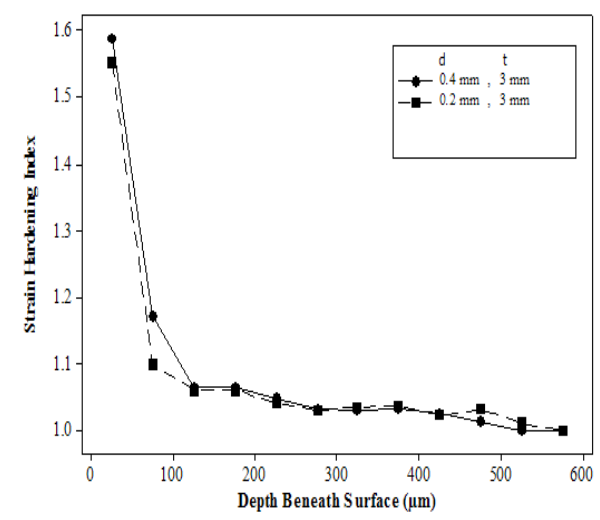

Figure 13. Variation of Strain Hardening Index with $\delta$

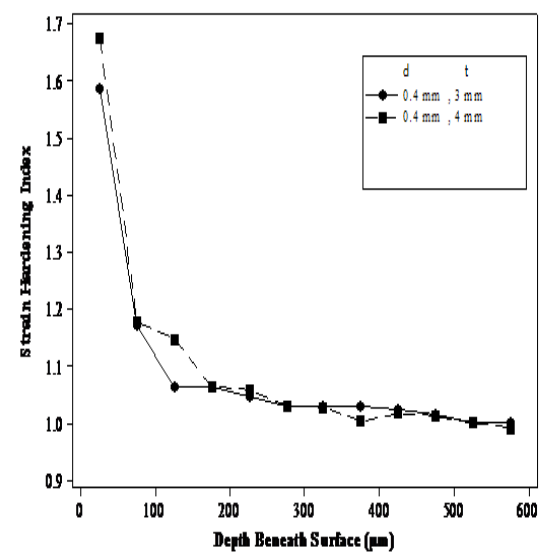

Figure 14. Variation of Strain Hardening Index with Depth Beneath Ballized Surface.

\subsection{Confirmation Tests}

In this study the optimum combination of the factor levels for both surface roughness and residual stress were not found in the OA (experimental plan). It has also been observed that the optimal settings of parameters for surface roughness and residual stress are quite different but the factors are essentially the same. It is to be noted that the optimal levels of factors differ widely for both the objectives.
In this study, after determining the optimum conditions, a new experiment was designed and conducted with the optimum levels to predict and verify the improvement of the performance characteristics. The confirmation experiment is performed by comparing between a test with specific combination of the factors and level previously evaluated and the optimum combination. In this study, the best combination in the OA was selected for comparing process. The verification of the test results is given in Table 6 .

As shown in this table, the improvement of the observed values of surface roughness and residual stress was $1.345 \mathrm{~dB}$ and $0.686 \mathrm{~dB}$ respectively. Based on the experimental confirmation the residual stress is increased by 1.08 times and surface roughness is decreased by 1.166 times.It is a good idea to analyze the observed value and the calculated value at the optimum condition. These confirmation tests serve two purposes. First, they establish the new performance at the new (optimum) condition, which can establish the improvement achieved. Second, they allow the experimenter to determine how close the estimate is to the results observed. The result expected is considered to be confirmed when the mean of a number of samples tested at the optimum condition falls close to it.

Table (7) showed the comparison of the predicted values with the actual values using the optimum combinations, a much lower differences were observed and the differences fall within the reasonable limit. As shown in this table, the experimental values agree reasonably well with the predictions because an error of $6.95 \% \mathrm{f}$ the $(S / N)$ ratio of SR and $0.80 \%$ for the $(S / N)$ ratio of RS is observed when predicted results are compared with experimental values at optimum combination. Hence, the experimental result confirms the optimization of the process parameters using Taguchi method for enhancing the process performance. The resulting model seems to capable of predicting the responses of the process to a reasonable accuracy.

Table 6. Results of the Confirmation Tests

\begin{tabular}{|c|c|c|c|c|}
\hline & \multirow{2}{*}{$\begin{array}{l}\text { Combination of } \\
\text { best experiment in } \\
\text { the } 0 \mathrm{~A}\end{array}$} & \multicolumn{3}{|c|}{ 0ptimal combination } \\
\hline & & \multicolumn{2}{|c|}{$\begin{array}{l}\text { Observed } \\
\text { Improvement }\end{array}$} & Predicted \\
\hline Combination levels & $\mathrm{A} 3 \mathrm{~B} 4 \mathrm{C} 2 \mathrm{D} 1 \mathrm{E} 2$ & \multicolumn{2}{|c|}{$\mathrm{A} 3 \mathrm{~B} 4 \mathrm{C} 2 \mathrm{D} 3 \mathrm{E} 2$} & \\
\hline Surface & 0.28 & 0.24 & 0.26 & $14.28 \%$ \\
\hline Roughness(Ra,um) & 11.05 & 12.395 & 11.528 & $12.17 \%$ \\
\hline \multicolumn{5}{|l|}{ S/NRatio (dB) } \\
\hline Combination levels & $\mathrm{A} 3 \mathrm{~B} 4 \mathrm{C} 2 \mathrm{D} 1 \mathrm{E} 2$ & \multicolumn{2}{|c|}{$\mathrm{A} 4 \mathrm{~B} 4 \mathrm{C} 2 \mathrm{D} 1 \mathrm{E} 1$} & \\
\hline Residual stress(MPa) & 258.24 & 279.16 & 292.14 & $8.10 \%$ \\
\hline S/NRatio (dB) & 48.24 & 48.917 & 49.312 & $1.40 \%$ \\
\hline
\end{tabular}


Table 7. Comparison Between the Observed Value and the Calculated Value at Optimum Combination

\begin{tabular}{|c|c|c|c|c|c|c|c|c|c|}
\hline \multirow[t]{2}{*}{ Response } & \multirow{2}{*}{$\begin{array}{l}\text { Optimum } \\
\text { Combination }\end{array}$} & \multicolumn{5}{|c|}{ Verification test result } & \multirow{2}{*}{$\frac{\text { Calculated }}{\text { Value } \eta_{\text {:alcu }}}$} & \multirow{2}{*}{$\begin{array}{l}\text { Difference } \\
\mid \eta_{\text {ver }}-\eta_{\text {calku }}\end{array}$} & \multirow{2}{*}{$\begin{array}{c}\text { Error } \\
\%\end{array}$} \\
\hline & & $\mathrm{Yl}$ & $\mathrm{Y} 2$ & $\mathrm{Y} 3$ & ymean & $\eta_{\mathrm{wer}}$ & & & \\
\hline $\begin{array}{l}\text { Surface } \\
\text { Roughness }\end{array}$ & A3B4C:D3E2 & 0.239 & 0.224 & 0.257 & $0.24 \mu \mathrm{m}$ & $12.39 \mathrm{~dB}$ & $11.528 \mathrm{~dB}$ & 0.862 & 6.95 \\
\hline $\begin{array}{l}\text { Residual } \\
\text { Stresses }\end{array}$ & AABACDDIEl & 281.34 & 279.16 & 277.82 & 279.4.MIPa & $48.92 \mathrm{~dB}$ & $49.312 \mathrm{~dB}$ & 0.392 & 0.80 \\
\hline
\end{tabular}

\section{CONCLUSIONS}

The purpose of this investigation is to demonstrate an application of Taguchi parameter design in order to identify the near optimum performance of the ballizing process.The following conclusions are drawn from the invstigation:

1- The parameter design of the Taguchi method provides a simple, systematic, and efficient methodology for the optimization of the ballizing parameters under limited number of experimental runs.

2- The Initial surface finish, the wall thickness and interference are the main parameters among the controllable factors that influence the roughness, of the ballized surface. The initial surface finish has the largest effect and thus has the most significant influence on the surface roughness of the ballized component. For manufacturing fine surface, a fine initial surface finish of the workpiece is advised. The thicker the wall thickness, the less the wall elasticity and more the surface finish improvement. The interference required to cause complete plastic deformation of the ring depends on both material properties and the wall thickness. When the wall thickness is small, a small interference is sufficient to complete plastic deformation as material can expand readily outwards. The experimental results indicate that no significant improvement in surface finish can be achieved when interference exceed that which is required to cause complete plastic deformation of the ring, any excessive interference would only mean high ballizing force and possible damage of ring material.

3- The interference, wall thickness and ball speed are the main parameters among the controllable factors that influence the residual stresses. Maximum wall thickness and maximum interference can be set for obtaining the maximum compressive residual stress at the ballized surface.

4- The microhardness just below the ballized surface is high. It decreases with an increase in the depth beneath the ballized surface eventually reaching the bulck hardness of the work material. The maximum value of the strain hardening increases with an increase in both interference and wall thickness. It's value then decreased very rapidly to a minimum at depths in the range of $300 \mu \mathrm{m}$ below the ballized surface (the depth of the plastically deformed layer) and tending to become constant. The microhardness just below the ballized surface was improved up to $65 \%$.

5- The results of confirmation experimental agree will with the predicted optimal settings as an error of $6.95 \%$ was observed for surface roughness. Similarly, an error of $0.8 \%$ was observed for residual stresses. Based on the experimental confirmation the residual stress is improved by $8.1 \%$ and surface roughness is improved by $14.28 \%$.

\section{REFERENCES}

[1] L.K.Gillespie," Hole in three ", Cutting Tool Eng. Magazine , Vol.61, Issue.3, march 2009.

[2] M.O. Lai, Y.H. Siew "Fatigue properties of cold worked holes ", journal of Materials Processing Technology 48 533-540,1995.

[3] M.Fattouh "Some investigations on the ballizing process ", Wear, vol. 134, No2, pp 209-219, Nov. 1989.

[4] National Ball-o-Matic-850 Mandoline, Madison heights, Michigan L. 48071, USA.

[5] K.H. Wang, L.A. Blunt, and K. stout, "The 3-D characterization of the surface topograghy of the ballizing process", In T.J. Mach. Tools Manufactured, Vol.38, PP.437-444, 1998.

[6] S.Z.EL-Abden, M.Abd El Rahman, and M. A. Mohamed," Finishing of non-ferrous internal surfaces using Ballizing Technique", J Mater. Processing tech. 124, 144-152, 2002.

[7] A.Y.C. Nee, "On the development of ballizing nomograms", InT.J.Mach. Tool Des.Res.Vol. 26, No.3.PP.293-306, 1986.

[8] K.H. Wang, L.A., Blunt, and K.," The effects of operational parameters on surface characteristics of the ballised material", Vol. 41, Issue 13-14, pp 2071-2078, 2001.

[9] B.Chennakesava Rao,P.N.Reddy and M.Komaraiah, "Some studies on spring back in ballizing process", Dep. of Mech. Osmania unv.Hyderabad 500 007, 17 proceedings of All India Manufacturing Technology, pp 101, Jan 1997.

[10] A.Y.C. Nee, V.C. Venkatesh ," A Study of the Ballizing Process" Manufacturing Technology, Vol. 30, Issue 1, pp 505-508,1981.

[11] A.Y.C. Nee, V.C. Venkatesh ," Bore finishingThe ballizing process"'Journal of Mechanical Working Technology, Vol. 6, Issue 2-3, pp 215226, March 1982.

[12] A.Y.C. Nee, V.C. Venkatesh ," A Mathematical Analysis of the Ball-Burnishing Process" Manufacturing Technology, Vol. 32, Issue 1, pp 201-204, 1983. 
[13] A.Y.C. Nee, V.C. Venkatesh ," Dry and lubricated ballizing " Tribology International, Vol. 17, Issue 1, pp 25-29, Feb. 1984.

[14] M.O.Lai,J.T.Oh ,A.Y.CNee," A review of ballising Cold working and its effect on fatigue life" journal of materials processing technology, vol. 23,Issue 2, pp. 163-176, oct. 1990.

[15] M .O.Lai, J.T.Oh, A.Y.C.Nee," Effect of residual stress on the fatigue performance of the surface of a ballised hole " journal of materials processing technology, vol. 29,Issue 1-3, pp 301-309, Jan 1992.

[16] M .O.Lai, J.T.Oh, A.Y.C.Nee," Fatigue properties of holes with residual stresses " Engineering Fracture mechanics, vol. 45,Issue 5, pp 551-557, Jul. 1993.

[17] J.T.Oh ," Stress analysis of a ballised hole" journal of materials processing technology, vol. 37,Issue 1-4, pp 137-147 Feb. 1993.
[18] M.O. Lai , Z. He, "Residual stress field of ballised holes", Journal of Mechanical Science and Technology, Vol. 26, Issue 5, pp 15551565,2012 .

[19] Q. Xie, A.E. Bayoumi, L.A. Kendall and G.L. Sheldon ,"A study on residual stresses and tool wear induced by machining processes", Transaction of the north American Manufacturing Research Institution of SME, pp170-174,1989.

[20] A.B. Sadat and J.A. Bailey,"Residual stress in turned AISI 4340 steel", Experimental Mechanics ,vol. 27, pp80-85,1987.

[21] P.J.Ross, "Taguchi techniques for quality eng." , McGrawill, 1989.

[22] M.Nalbant,H. Gokkaya, and G.Sur, "Application of Taguchi method in the optimization of cutting parameters for surface roughness", Materials, Design 28 1379-1385, 2007. 